\title{
Variability of hemodynamic parameters using the common viscosity assumption in a computational fluid dynamics analysis of intracranial aneurysms
}

\author{
Takashi Suzuki ${ }^{\mathrm{a}}$, Hiroyuki Takao a,b,c,*, Takamasa Suzuki ${ }^{\mathrm{d}}$, Tomoaki Suzuki ${ }^{\mathrm{b}}$, \\ Shunsuke Masuda ${ }^{\mathrm{b}}$, Chihebeddine Dahmani ${ }^{\mathrm{b}, \mathrm{e}}$, Mitsuyoshi Watanabe ${ }^{\mathrm{b}}$, Hiroya Mamori ${ }^{\mathrm{f}}$, \\ Toshihiro Ishibashi $^{\mathrm{b}}$, Hideki Yamamoto ${ }^{\mathrm{d}}$, Makoto Yamamoto ${ }^{\mathrm{f}}$ and Yuichi Murayama ${ }^{\mathrm{b}}$ \\ ${ }^{a}$ Graduate School of Mechanical Engineering, Tokyo University of Science, Tokyo, Japan \\ ${ }^{\mathrm{b}}$ Division of Endovascular Neurosurgery, Department of Neurosurgery, The Jikei University School of \\ Medicine, Tokyo, Japan \\ ${ }^{\mathrm{c}}$ Department of Innovation for Medical Information Technology, The Jikei University School of \\ Medicine, Tokyo, Japan \\ ${ }^{\mathrm{d}}$ Department of Chemical, Energy and Environment Engineering, Kansai University, Osaka, Japan

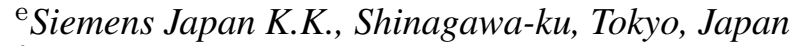 \\ ${ }^{\mathrm{f}}$ Department of Mechanical Engineering, Tokyo University of Science, Tokyo, Japan
}

Received 10 February 2016

Accepted 2 June 2016

\begin{abstract}
.
BACKGROUND: In most simulations of intracranial aneurysm hemodynamics, blood is assumed to be a Newtonian fluid. However, it is a non-Newtonian fluid, and its viscosity profile differs among individuals. Therefore, the common viscosity assumption may not be valid for all patients.

OBJECTIVE: This study aims to test the suitability of the common viscosity assumption.

METHODS: Blood viscosity datasets were obtained from two healthy volunteers. Three simulations were performed for three different-sized aneurysms, two using measured value-based non-Newtonian models and one using a Newtonian model. The parameters proposed to predict an aneurysmal rupture obtained using the non-Newtonian models were compared with those obtained using the Newtonian model.

RESULTS: The largest difference (25\%) in the normalized wall shear stress (NWSS) was observed in the smallest aneurysm. Comparing the difference ratio to the NWSS with the Newtonian model between the two Non-Newtonian models, the difference of the ratio was $17.3 \%$.

CONCLUSIONS: Irrespective of the aneurysmal size, computational fluid dynamics simulations with either the common Newtonian or non-Newtonian viscosity assumption could lead to values different from those of the patient-specific viscosity model for hemodynamic parameters such as NWSS.
\end{abstract}

\footnotetext{
${ }^{*}$ Corresponding author: Hiroyuki Takao, Division of Endovascular Neurosurgery, Department of Neurosurgery, The Jikei University School of Medicine, 3-25-8 Nishi-Shinbashi, Minato-ku, Tokyo 105-8461, Japan. Tel.: +81 33433 3461; Fax: +81 33459 6412; E-mail: takao@jikei.ac.jp.
}

0928-7329/17/\$35.00 (c) 2017 - IOS Press and the authors. All rights reserved This article is published online with Open Access and distributed under the terms of the Creative Commons Attribution NonCommercial License (CC BY 4.0). 
Keywords: Computational fluid dynamics, intracranial aneurysm, viscosity, non-Newtonian viscosity, wall shear stress, Casson model

\section{Introduction}

The rupture of an aneurysm can cause subarachnoid hemorrhage, a very serious condition that is often fatal. However, many patients have aneurysms that never rupture. Therefore, the risks and benefits of surgical treatment should be carefully considered. Even though the risk of rupture generally increases as the size of the aneurysm increases [1], small aneurysms can also rupture. Therefore, an accurate diagnosis is difficult, and aneurysms may rupture during follow-up. At present, there are no objective criteria for evaluation and diagnosis, and whether an operation should be performed depends on the knowledge and experience of the physician.

Computational fluid dynamics (CFD) has been used to clarify the mechanisms of aneurysmal initiation, growth, and rupture and to predict these by processing various hemodynamic parameters such as wall shear stress (WSS) [2-10], which is the tangential frictional stress of blood flowing along the vascular wall and is widely considered to be associated with rupture. Both high [3-5] and low $[6,8,10]$ WSS have been correlated with aneurysmal growth and rupture. On the basis of these inconsistent reports, Meng et al. proposed a unified hypothesis stating that both high and low WSS play an important role in the rupture of intracranial aneurysms (IAs) [11]. However, predicting the rupture of an individual aneurysm is still a matter of active research, and suitable hemodynamic parameters are still being investigated. To perform the investigations described above, an accurate model of blood viscosity is required [12].

In previous IA simulations, blood has been modeled as a Newtonian fluid and/or the arterial wall has been considered rigid as a simplification. In addition, several common conditions such as velocity at the inlet boundary, blood viscosity, and blood density have been used owing to lack of patient-specific data. However, blood is a non-Newtonian fluid and exhibits a shear-thinning behavior; its viscosity changes depending on the shear strain rate and differs among individuals and in the same individual at different points in time. In particular, viscosity increases in low strain-rate fields and converges in high strain-rate fields [13].

The importance of non-Newtonian effects on blood flow simulations has been studied. Gijsen et al. [14] compared a Newtonian and a non-Newtonian model in a steady flow analysis of a carotid bifurcation model computationally and experimentally and showed that the influence of the shear thinning properties on the velocity distribution in larger arteries strongly depends on slight variations in the shear rate. Cebral et al. [15] performed a sensitivity analysis on the viscosity model and showed that even though changes in the velocity fields could be observed, the characterization of the intra-aneurysmal flow patterns was not altered. Valencia et al. [16] showed some differences in the WSS in arterial regions with high-velocity gradients but concluded that the solutions such as WSS with a Newtonian and a non-Newtonian blood model were similar on the IA wall. Fisher and Rossmann [17] showed considerable differences between the results with a Newtonian and non-Newtonian models but concluded that they were not as significant as the changes seen among varying IA morphologies. Xiang et al. [18] observed that a Newtonian viscosity model could overestimate WSS in IA domes and underestimate rupture risk. Evju et al. [19] compared four different viscosity models in twelve IA cases and demonstrated strong correlations between the viscosity models. Hippelheuser et al. [20] investigated the effect of employing the simplified assumption of constant viscosity, particularly in cases with a bleb, and reported 


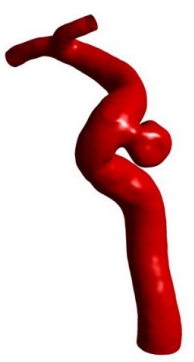

case A

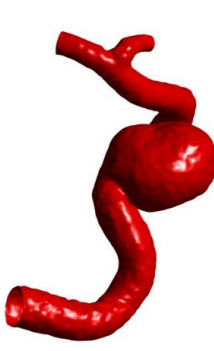

case B

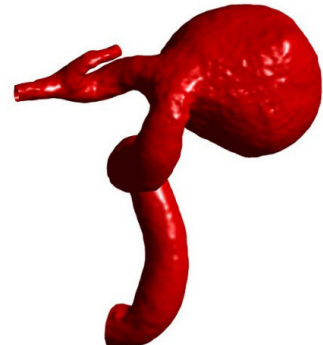

case $\mathrm{C}$

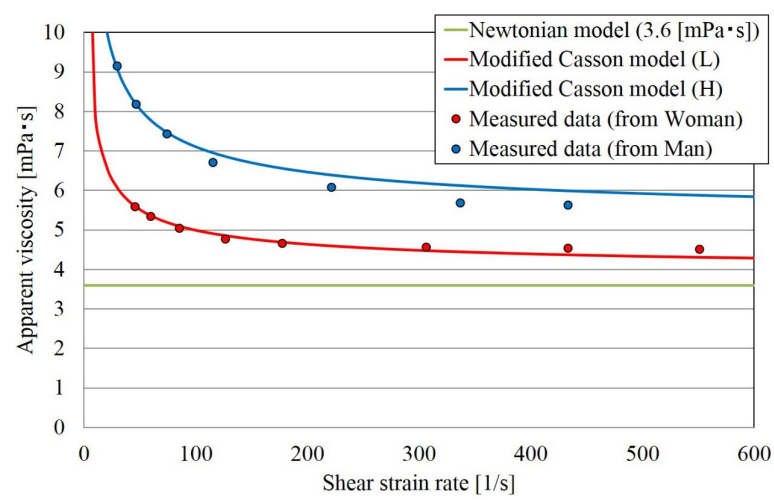

Fig. 2. The relationships between the viscosity and shear strain rates of the measured data and the viscosity models. "Casson-L" and "Casson-H" indicate the modified Casson model derived from the lower measured data (from a woman) and the higher measured data (from a man), respectively.

that adopting a non-Newtonian viscosity model highlighted the hemodynamic differences induced by the presence of a bleb and improved the discriminant statistics in rupture prediction.

The previous studies described above used typical values for the constants in the non-Newtonian models. In actuality, blood viscosity profiles differ between individuals [13]. Accordingly, the viscosity assumption may not be adaptable for all patients, and verifications of the viscosity assumption have been insufficient. In this study, to verify the common Newtonian viscosity assumption, the CFD simulation results with the Newtonian viscosity model are compared with those of actual viscosity data obtained from human subjects.

\section{Materials and methods}

Three different-sized internal carotid artery aneurysms (approximately 5, 10, and $20 \mathrm{~mm}$ in diameter) were randomly selected from the database at our institution (Fig. 1). All three were unruptured cases: case A (height: $4.5 \mathrm{~mm}$, width: $4.9 \mathrm{~mm}$ ), case B (height: $11.3 \mathrm{~mm}$, width: $12.4 \mathrm{~mm}$ ), and case C (height: $19.2 \mathrm{~mm}$, width: $20.1 \mathrm{~mm}$ ). The clinical images were acquired using biplane angiography (AXIOM Artis dBA, Siemens AG, Munich, Germany) and a post-processing workstation (syngo XWP, Siemens AG). The imager was equipped with two $30 \times 40 \mathrm{~cm}$ flat plane detectors and was able to acquire rotational $3 \mathrm{D}$ and 3D digital subtraction angiography datasets (syngo InSpace 3D). Three-dimensional voxel models were reconstructed using Amira (FEI/VSG-division, Bordeaux, France). After the extraction of each control domain and smoothing, all the data were converted to a stereolithographic (STL) format. Based on these STL format data, unstructured volume grids were generated by ICEM CFD 14.5 (ANSYS, Inc., Canonsburg, PA, USA) using tetrahedral elements with a maximum size of $0.2 \mathrm{~mm}$ and prism grids. The prism grids were fitted to the wall, with the first layer having a thickness of $0.02 \mathrm{~mm}$ and the remaining seven layers having a total thickness of $0.3 \mathrm{~mm}$. Grid independent tests were performed to ensure grid independency in all cases and confirm that the grid size was adequate to obtain the comparison results independent of its value. The total number of elements in the meshes ranged from approximately 3.5 to 19.5 million. The incompressible continuity and Navier-Stokes equations were solved using CFX 14.5 (ANSYS, Inc.). To investigate the effect of viscosity alone, the other conditions were kept constant in 
all simulations. Unsteady flow analysis was conducted over three heartbeats $(2.7 \mathrm{~s})$ with a time step of $5 \times 10^{-4} \mathrm{~s}$. Data from the last cycle were used. The mass flow rate waveform [21] was imposed at the inlet boundary. In the flow field, laminar flow was assumed because the Reynolds number, based on the diameter of the internal carotid arteries, was less than 500. At the outflow boundary, the pressure was fixed to $0 \mathrm{~Pa}$. Rigid and non-slip boundary conditions were assumed on all the vascular walls. The blood density was assumed to be $1,100 \mathrm{~kg} / \mathrm{m}^{3}$.

The Casson model is widely used to model blood flow in narrow arteries at low strain rates [22]. The apparent viscosity of this model is given as follows [23]:

$$
\mu=\left(\sqrt{\frac{\tau_{0}}{\dot{\gamma}}}+\sqrt{\mu_{0}}\right)^{2},
$$

where $\tau_{0}$ and $\mu_{0}$ are the yield stress and the Newtonian viscosity, respectively, and $\dot{\gamma}$ is the strain rate. Because this classic Casson model diverges when the strain rate becomes zero, it is usually modified as follows [23]:

$$
\mu=\left[\sqrt{\tau_{0}\left(\frac{1-e^{-m \dot{\gamma}}}{\dot{\gamma}}\right)}+\sqrt{\mu_{\infty}}\right]^{2},
$$

where the parameter $m$ controls the maximum viscosity obtained when $\dot{\gamma}$ tends to zero.

The blood viscosity datasets were obtained from a healthy man (age: $22 \mathrm{y}$, hematocrit [Ht]: 46.7\%) and woman (age: $22 \mathrm{y}, \mathrm{Ht}: 35.6 \%$ ) using a compact-sized falling needle rheometer [13,24]. These data were fitted to modified Casson models. Figure 2 shows two plots of measured data and two modified Casson models fitted using these data. $\tau_{0}$ and $\mu_{0}$ were calculated from two points measured when the strain rate attained the lowest and the second lowest values (represented as the Casson- $\mathrm{H}$ (High) model: $\tau_{0}=0.0177 \mathrm{~Pa}$ and $\mu_{0}=0.00504 \mathrm{~Pa} \cdot \mathrm{s}$ and the Casson-L (Low) model: $\tau_{0}=0.00768 \mathrm{~Pa}$ and $\mu_{0}=$ $0.00383 \mathrm{~Pa} \cdot \mathrm{s})$.

Three simulations were conducted for each case: two using measured value-based modified Casson models and one using a Newtonian model. In the simulations with the Newtonian model, a typical value of $0.0036 \mathrm{~Pa} \cdot \mathrm{s}$ was used for the viscosity $[9,25]$. In the viscosity models, viscosity values were set in the increasing order of Casson-H $>$ Casson-L $>$ Newtonian.

Hemodynamic parameters (WSS, maximum WSS (MWSS) [5], normalized WSS (NWSS) [6], normalized maximum WSS (NMWSS) [6], energy loss (EL) [7], and pressure loss coefficient (PLc) [9]) obtained using the non-Newtonian models were compared with those using the Newtonian model. All parameters in this study were time-averaged over one cardiac cycle. WSS and MWSS were defined as the spatially averaged and the maximum WSS over the entire aneurysm sac, respectively. NWSS and NMWSS were defined as WSS and the maximum aneurysmal WSS normalized by the time-averaged and spatially averaged WSS over the parent artery, respectively. In addition, the WSS (spatially averaged WSS) at the parent artery was computed to clarify the basic viscosity (viscosity in a high shear strain field) effect on the CFD.

\section{Results}

The values of each parameter are given in Table 1 . The velocity is the average value of the intraaneurysmal velocity. The average velocity decreased with increasing IA size (Table 1(a)). Moreover, 


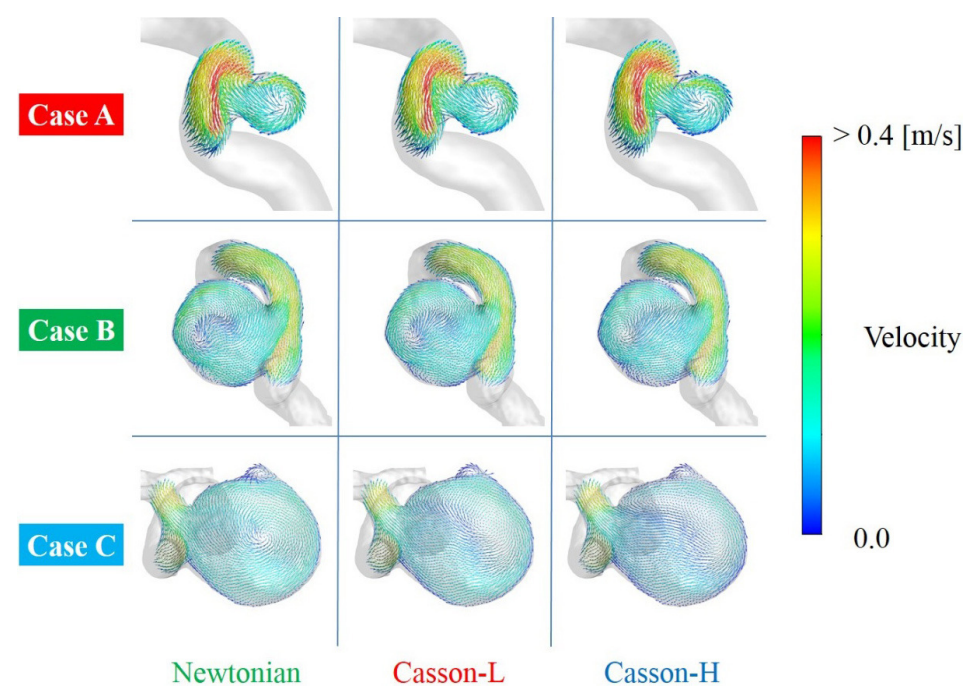

Fig. 3. Velocity vector field at end diastole on a representative cross-sectional plane.

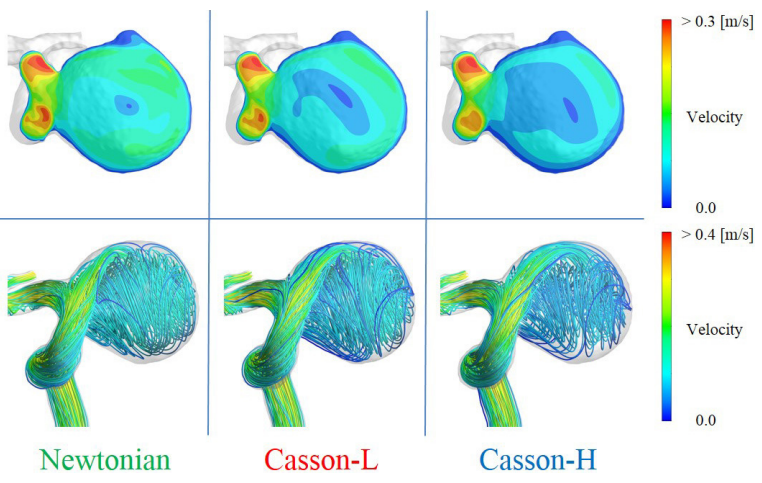

Fig. 4. Velocity distribution on a representative cross-sectional plane and streamline in case $\mathrm{C}$ at end diastole.

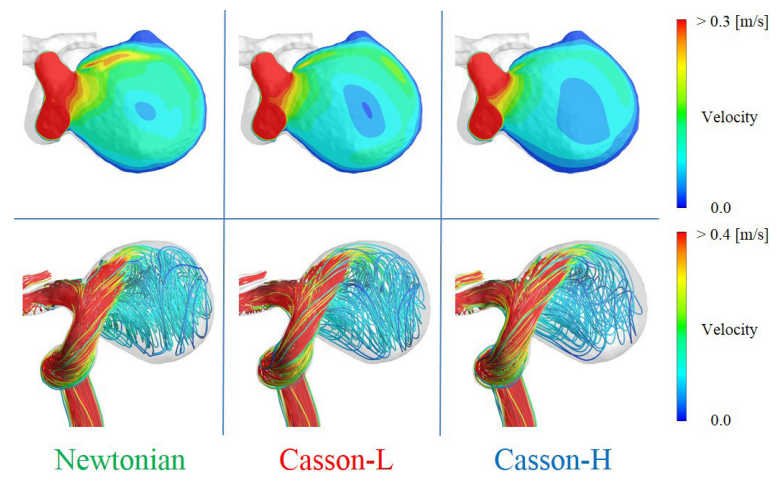

Fig. 5. Velocity distribution on a representative cross-sectional plane and streamline in case $\mathrm{C}$ at peak systole.

the velocity decreased from the model with the lowest viscosity (Newtonian) to that with the highest viscosity (Casson-H). Velocity vector fields at end diastole are shown in Fig. 3. Similar flow patterns are identified regardless of the viscosity model, especially in case A. However, in case B with the Casson$\mathrm{H}$ model, different velocity vector fields were identified on the right part of the vortex center in the aneurysmal dome. In case $\mathrm{C}$, all three results had different vortex center positions. Velocity fields on the cross-section in the aneurysmal dome and streamline in case $\mathrm{C}$ are shown in Figs 4 and 5, respectively. The different velocity fields and similar flow patterns described above are identified in the figures. Timeaveraged viscosities on the wall of the IA and parent artery, respectively, are shown in Tables 1(b) and 1(c). For all aneurysm sizes, viscosity was larger on the aneurysmal wall than on the parent artery in the non-Newtonian models. Time-averaged viscosity distributions are shown in Fig. 6. Viscosity on the aneurysmal wall in the non-Newtonian models increased with increasing IA size. This means that an increase in the IA size led to an increase in the non-Newtonian effects.

Time-averaged WSS distributions are shown in Fig. 7. In all cases, a partial change in the WSS value is identified in the results of the non-Newtonian models compared to those obtained with the Newtonian 
Table 1

Absolute values of the parameters, differences of the parameters from the result with the Newtonian model, and ratios of the parameters to the result of the Newtonian model. Newtonian, Casson-L, and Casson-H represent the results with the Newtonian model, Casson-L model, and Casson-H model, respectively

\begin{tabular}{cllcc}
\hline (a) & \multicolumn{2}{c}{ Velocity [m/s] } & $\begin{array}{c}\text { Difference from } \\
\text { the Newtonian } \\
\text { model [m/s] }\end{array}$ & $\begin{array}{c}\text { Ratio to the } \\
\text { Newtonian } \\
\text { model [\%] }\end{array}$ \\
\hline Case A & Newtonian & 0.202 & 0 & 100 \\
& Casson-L & 0.191 & -0.012 & 94.3 \\
& Casson-H & 0.166 & -0.036 & 82.2 \\
Case B B & Newtonian & 0.167 & 0 & 100 \\
& Casson-L & 0.161 & -0.006 & 96.5 \\
& Casson-H & 0.149 & -0.018 & 89.3 \\
Case C C Newtonian & 0.116 & 0 & 100 \\
& Casson-L & 0.104 & -0.012 & 89.8 \\
& Casson-H & 0.085 & -0.031 & 73.2 \\
\hline
\end{tabular}

\begin{tabular}{|c|c|c|c|c|}
\hline (c) & $\begin{array}{r}\text { Viscos } \\
\left(\times 10^{-3}\right) \\
\text { parent arter }\end{array}$ & $\begin{array}{l}\text { ty } \\
\text { at the } \\
{[\mathrm{Pa} \mathrm{s}]}\end{array}$ & $\begin{array}{c}\text { Difference from } \\
\text { the Newtonian } \\
\text { model }[\mathrm{Pa} \mathrm{s}]\end{array}$ & $\begin{array}{l}\text { Ratio to the } \\
\text { Newtonian } \\
\text { model [\%] }\end{array}$ \\
\hline Case A & $\begin{array}{l}\text { Newtonian } \\
\text { Casson-L } \\
\text { Casson-H }\end{array}$ & $\begin{array}{l}3.600 \\
4.159 \\
5.665\end{array}$ & $\begin{array}{c}0 \\
0.559 \\
2.065\end{array}$ & $\begin{array}{c}100 \\
115.5 \\
157.4\end{array}$ \\
\hline Case B & $\begin{array}{l}\text { Newtonian } \\
\text { Casson-L } \\
\text { Casson-H }\end{array}$ & $\begin{array}{l}3.600 \\
4.290 \\
5.883\end{array}$ & $\begin{array}{c}0 \\
0.690 \\
2.283\end{array}$ & $\begin{array}{c}100 \\
119.2 \\
163.4\end{array}$ \\
\hline Case C & $\begin{array}{l}\text { Newtonian } \\
\text { Casson-L } \\
\text { Casson-H }\end{array}$ & $\begin{array}{l}3.600 \\
4.253 \\
5.815\end{array}$ & $\begin{array}{c}0 \\
0.653 \\
2.215\end{array}$ & $\begin{array}{c}100 \\
118.1 \\
161.5\end{array}$ \\
\hline
\end{tabular}

\begin{tabular}{clccc}
\hline (b) & \multicolumn{2}{c}{$\begin{array}{c}\text { Viscosity } \\
\left(\times 10^{-3}\right) \text { at the } \\
\text { aneurysm }[\mathrm{Pa} \mathrm{s}]\end{array}$} & $\begin{array}{c}\text { Difference from } \\
\text { the Newtonian } \\
\text { model [Pa s] }\end{array}$ & $\begin{array}{c}\text { Ratio to the } \\
\text { Newtonian } \\
\text { model [\%] }\end{array}$ \\
\hline Case A & $\begin{array}{c}\text { Newtonian } \\
\text { Casson-L }\end{array}$ & 3.600 & 0 & 100 \\
& Cast & 0.627 & 117.4 \\
& Casson-H & 5.916 & 2.316 & 164.3 \\
Case B & Newtonian & 3.600 & 0 & 100 \\
& Casson-L & 4.418 & 0.818 & 122.7 \\
& Casson-H & 6.256 & 2.656 & 173.8 \\
Case C Cewtonian & 3.600 & 0 & 100 \\
& Casson-L & 4.760 & 1.160 & 132.2 \\
& Casson-H & 7.074 & 3.474 & 196.5 \\
\hline
\end{tabular}

\begin{tabular}{clccc}
\hline (d) & \multicolumn{1}{c}{ WSS [Pa] } & $\begin{array}{c}\text { Difference from } \\
\text { the Newtonian } \\
\text { model [Pa] }\end{array}$ & $\begin{array}{c}\text { Ratio to the } \\
\text { Newtonian } \\
\text { model [\%] }\end{array}$ \\
\hline Case A & Newtonian & 4.971 & 0 & 100 \\
& Casson-L & 4.925 & -0.046 & 99.1 \\
& Casson-H & 4.715 & -0.256 & 94.9 \\
Case B & Newtonian & 2.360 & 0 & 100 \\
& Casson-L & 2.478 & 0.118 & 105.0 \\
& Casson-H & 2.675 & 0.315 & 113.4 \\
Case C & Newtonian & 0.959 & 0 & 100 \\
& Casson-L & 1.053 & 0.095 & 109.9 \\
& Casson-H & 1.096 & 0.138 & 114.4 \\
\hline \hline
\end{tabular}

\begin{tabular}{cllcc}
\hline (e) & \multicolumn{2}{c}{$\begin{array}{c}\text { WSS at parent } \\
\text { artery [Pa] }\end{array}$} & $\begin{array}{c}\text { Difference from } \\
\text { the Newtonian } \\
\text { model [Pa] }\end{array}$ & $\begin{array}{c}\text { Ratio to the } \\
\text { Newtonian } \\
\text { model [\%] }\end{array}$ \\
\hline Case A & Newtonian & 7.429 & 0 & 100 \\
& Casson-L & 7.962 & 0.533 & 107.2 \\
& Casson-H & 9.392 & 1.963 & 126.4 \\
Case B B & Newtonian & 3.972 & 0 & 100 \\
& Casson-L & 4.329 & 0.357 & 109.0 \\
& Casson-H & 5.149 & 1.176 & 129.6 \\
Case C & Newtonian & 4.148 & 0 & 100 \\
& Casson-L & 4.609 & 0.461 & 111.1 \\
& Casson-H & 5.582 & 1.435 & 134.6 \\
\hline
\end{tabular}

\begin{tabular}{clccc}
\hline (f) & \multicolumn{2}{c}{ MWSS [Pa] } & $\begin{array}{c}\text { Difference from } \\
\text { the Newtonian } \\
\text { model [Pa] }\end{array}$ & $\begin{array}{c}\text { Ratio to the } \\
\text { Newtonian } \\
\text { model [\%] }\end{array}$ \\
\hline Case A & Newtonian & 34.633 & 0 & 100 \\
& Casson-L & 36.164 & 1.531 & 104.4 \\
& Casson-H & 40.602 & 5.969 & 117.2 \\
Case B & Newtonian & 24.152 & 0 & 100 \\
& Casson-L & 24.642 & 0.490 & 102.0 \\
& Casson-H & 27.315 & 3.163 & 113.1 \\
Case C C & Newtonian & 15.051 & 0 & 100 \\
& Casson-L & 16.686 & 1.635 & 110.9 \\
& Casson-H & 19.599 & 4.547 & 130.2 \\
\hline
\end{tabular}

\begin{tabular}{clccc}
\hline (g) & \multicolumn{1}{c}{ NWSS } & $\begin{array}{c}\text { Difference from } \\
\text { the Newtonian } \\
\text { model }\end{array}$ & $\begin{array}{c}\text { Ratio to the } \\
\text { Newtonian } \\
\text { model [\%] }\end{array}$ \\
\hline Case A & Newtonian & 0.669 & 0 & 100 \\
& Casson-L & 0.619 & -0.051 & 92.4 \\
& Casson-H & 0.502 & -0.167 & 75.0 \\
Case B & Newtonian & 0.594 & 0 & 100 \\
& Casson-L & 0.572 & -0.022 & 96.3 \\
& Casson-H & 0.520 & -0.074 & 87.5 \\
Case C & Newtonian & 0.231 & 0 & 100 \\
& Casson-L & 0.229 & -0.003 & 98.9 \\
& Casson-H & 0.196 & -0.035 & 85.0 \\
\hline
\end{tabular}

\begin{tabular}{clccc}
\hline (h) & \multicolumn{1}{c}{ MNWSS } & $\begin{array}{c}\text { Difference from } \\
\text { the Newtonian } \\
\text { mode }\end{array}$ & $\begin{array}{c}\text { Ratio to the } \\
\text { Newtonian } \\
\text { model [\%] }\end{array}$ \\
\hline Case A & Newtonian & 4.662 & 0 & 100 \\
& Casson-L & 4.542 & -0.120 & 97.4 \\
& Casson-H & 4.323 & -0.339 & 92.7 \\
Case B & Newtonian & 6.080 & 0 & 100 \\
& Casson-L & 5.692 & -0.388 & 93.6 \\
& Casson-H & 5.305 & -0.775 & 87.3 \\
Case C & Newtonian & 3.629 & 0 & 100 \\
& Casson-L & 3.620 & -0.008 & 99.8 \\
& Casson-H & 3.511 & -0.118 & 96.7 \\
\hline
\end{tabular}


Table 1, continued

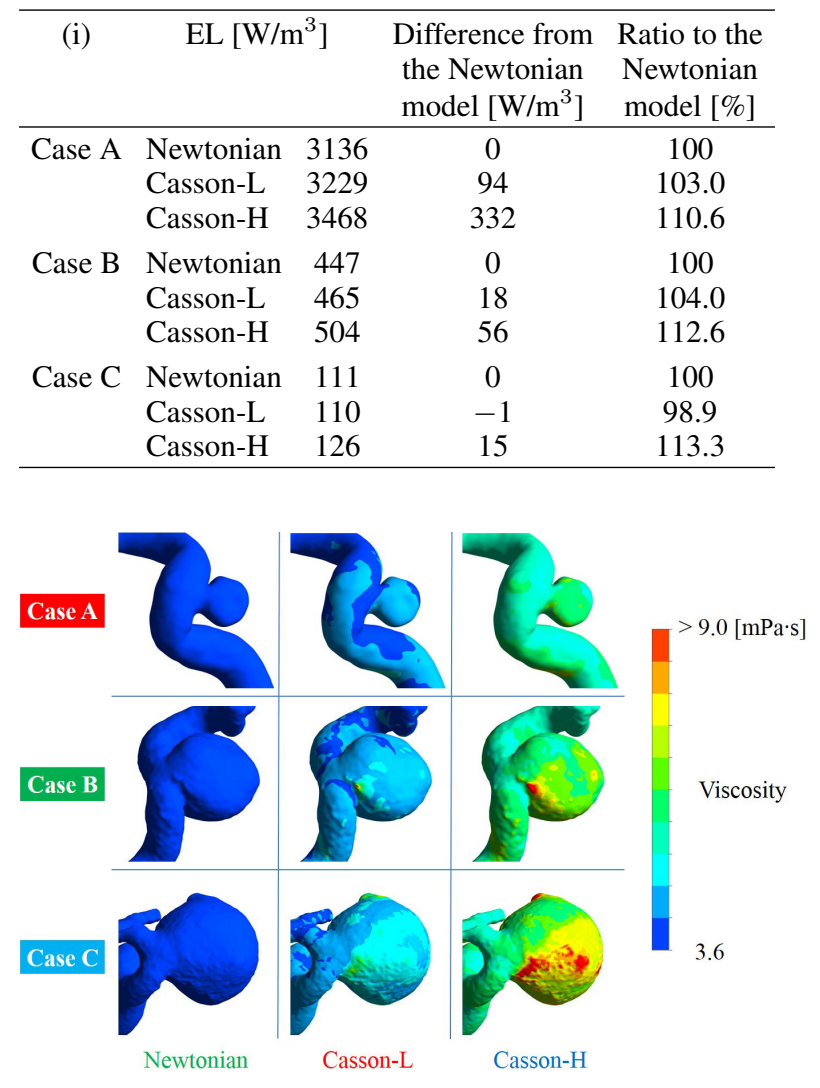

Fig. 6. Time-averaged viscosity distribution.

\begin{tabular}{clccc}
\hline (j) & PLc & $\begin{array}{c}\text { Difference from } \\
\text { the Newtonian } \\
\text { model }\end{array}$ & $\begin{array}{c}\text { Ratio to the } \\
\text { Newtonian } \\
\text { model [\%] }\end{array}$ \\
\hline Case A & Newtonian & 0.901 & 0 & 100 \\
& Casson-L & 0.926 & 0.025 & 102.8 \\
& Casson-H & 0.991 & 0.090 & 110.0 \\
Case B & Newtonian & 2.294 & 0 & 100 \\
& Casson-L & 2.417 & 0.122 & 105.3 \\
& Casson-H & 2.652 & 0.358 & 115.6 \\
Case C C Newtonian & 1.579 & 0 & 100 \\
& Casson-L & 1.722 & 0.143 & 109.1 \\
& Casson-H & 1.897 & 0.317 & 120.1 \\
\hline
\end{tabular}

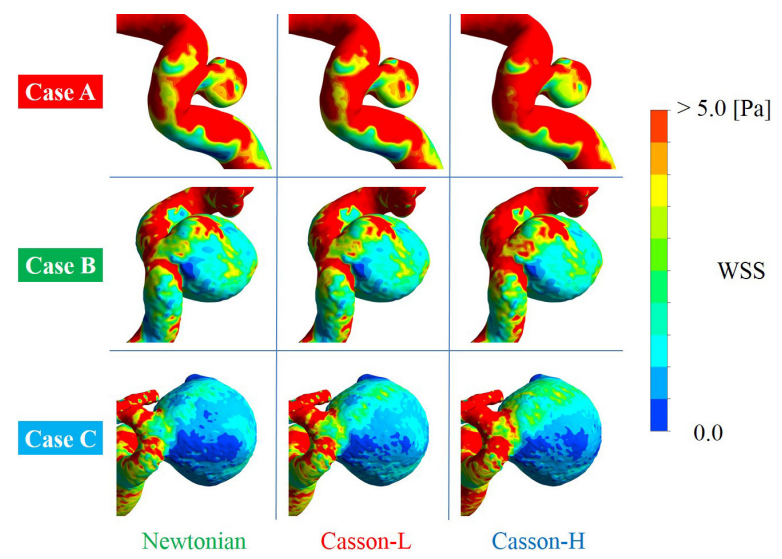

Fig. 7. Time-averaged WSS distribution.

model. However, the distributions of the high and low WSS regions with the non-Newtonian models were similar to those with the Newtonian model.

The time-averaged WSS distributions normalized by the WSS values obtained with the Newtonian model are shown in Fig. 8. All the results obtained with the Newtonian model show a distribution of 1 because WSS in these cases was divided by itself. The results obtained with the non-Newtonian model show areas of markedly increased WSS. However, there are also areas where WSS is lower than that obtained with the Newtonian model. Therefore, the distributions show a mix of regions where the Newtonian model overestimates WSS and regions where the model underestimates WSS. These localized changes increased as the IA size increased. The localized changes were smaller on the parent arteries than on the aneurysmal domes.

WSS in case A decreased from the model with the lowest viscosity (Newtonian) to the model with the highest viscosity (Casson-H) (Table 1(d)). The largest disparity in case A was observed with the Casson$\mathrm{H}$ model. The WSS with that model was $94.9 \%$ of the WSS with the Newtonian model, meaning that the changes were negligible. In cases B and C, WSS increased from the model with the lowest viscosity (Newtonian) to the model with the highest viscosity (Casson-H). In all cases, the WSS at the parent artery increased from the model with the lowest viscosity (Newtonian) to that with the highest viscosity (Casson-H) (Table 1(e)). The largest disparity was observed with the Casson-H model in the largest case (case C), which was $134.6 \%$ of the WSS at the parent artery with the Newtonian model. 
Table 2

Comparison of the results between the non-Newtonian models. The differences of the ratios shown in Table 1 between the two non-Newtonian models (i.e., the ratio of the Casson-H model was subtracted from that of the Casson-L model)

\begin{tabular}{lrrr}
\hline Unit: \% & Case A & Case B & Case C \\
\hline Velocity $[\mathrm{m} / \mathrm{s}]$ & 12.1 & 7.2 & 16.5 \\
Viscosity $\left(\times 10^{-3}\right)$ & -46.9 & -51.0 & -64.3 \\
at the aneurysm $[\mathrm{Pa} \mathrm{s}]$ & & & \\
Viscosity $\left(\times 10^{-3}\right)$ & -41.8 & -44.3 & -43.4 \\
at the parent artery [Pa s] & & & \\
WSS [Pa] & 4.2 & -8.4 & -4.5 \\
WSS at parent artery & -19.2 & -20.6 & -23.5 \\
MWSS [Pa] & -12.8 & -11.1 & -19.4 \\
NWSS & 17.4 & 8.9 & 13.9 \\
MNWSS & 4.7 & 6.4 & 3.0 \\
EL [W/m ${ }^{3}$ ] & -7.6 & -8.6 & -14.4 \\
PLc & -7.2 & -10.3 & -11.0 \\
\hline
\end{tabular}

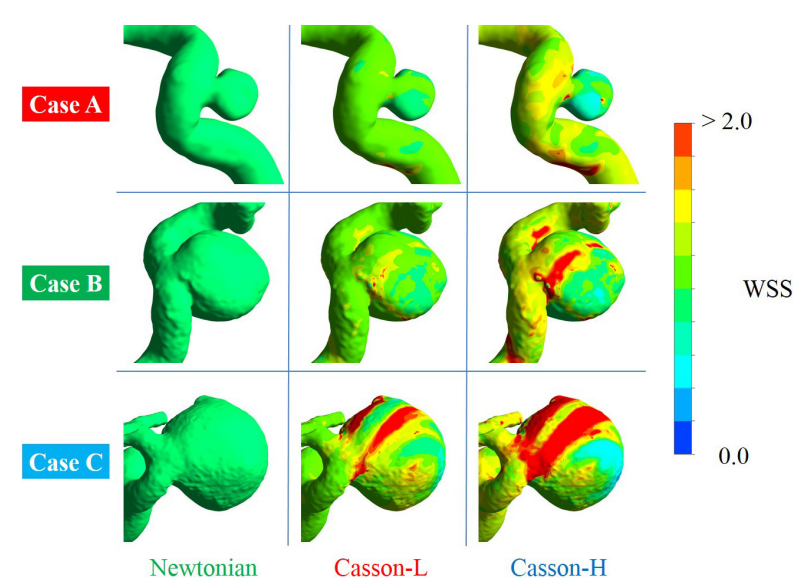

Fig. 8. Time-averaged WSS distribution normalized by local WSS values from the result with the Newtonian model.

MWSS increased from the model with the lowest viscosity (Newtonian) to the model with the highest viscosity (Casson-H), and decreased with increasing IA size (Table 1(f)). The largest disparity was observed with the Casson-H model in the largest case (case C), which was $130.2 \%$ of the MWSS with the Newtonian model. Differences of over $10 \%$ were observed with the Casson-H model regardless of IA size.

In all cases, NWSS decreased from the model with the lowest viscosity (Newtonian) to the model with the highest viscosity (Casson-H) (Table $1(\mathrm{~g})$ ). The largest disparity was observed with the Casson$\mathrm{H}$ model in the smallest case (case A), which was $75.0 \%$ of the NWSS with the Newtonian model. Differences of over $10 \%$ were observed with the Casson-H model regardless of IA size.

MNWSS decreased from the model with the lowest viscosity (Newtonian) to the model with the highest viscosity (Casson-H) (Table 1(h)). The largest disparity was observed with the Casson-H model in case B, which was $87.3 \%$ of the MNWSS with the Newtonian model.

EL decreased with increasing IA size (Table 1(i)). The largest disparity was observed with the Casson$\mathrm{H}$ model in case $\mathrm{C}$, which was $113.3 \%$ of the EL with the Newtonian model. Differences of over $10 \%$ were observed with the Casson-H model irrespective of IA size.

PLc increased from the model with the lowest viscosity (Newtonian) to the model with the highest viscosity (Casson-H) (Table 1(j)). The largest disparity was observed with the Casson-H model in case C, which was $120.1 \%$ of the PLc with the Newtonian model. Differences of over $10 \%$ were observed with the Casson-H model regardless of IA size.

Finally, in addition to the parameters described above, values of the average oscillatory shear index (OSI) over the entire aneurysm sac obtained using the non-Newtonian models were compared with those using the Newtonian model. As shown in previous studies $[6,10,26]$, the average OSI is generally low. Therefore, small differences lead to larger relative errors, and the average OSI likely depends on the grid size and computational conditions such as viscosity. Even though large differences in OSI between the results with Newtonian, Casson-L, and Casson-H models were identified (e.g., 0.0353, 0.0256 (72.6\%), and 0.0147 (41.7\%) in case C), we could not confirm the grid independence of these models and therefore did not include these data in the Tables. 


\section{Discussion}

Blood flow simulations considering blood viscosity with values obtained from human subjects were conducted using actual IA morphologies. Even though non-Newtonian effects of viscosity models on blood flow simulations have been examined in previous studies, this study is the first to compare two non-Newtonian models derived from actual values taken from human subjects. The fluid dynamic parameter values obtained with the non-Newtonian models derived from the actual viscosity values were compared with those obtained with the Newtonian model. Large discrepancies were observed between the results with the non-Newtonian model with higher viscosity and those with the Newtonian model for several parameters, especially MWSS and NWSS, where NWSS is the WSS value normalized by WSS on the parent artery. Data are typically normalized so that the results for different patients can be compared when a CFD analysis is performed using the same inflow conditions [27]. Our results show that the differences in the ratios between the Newtonian and non-Newtonian models were greater for the normalized WSS than for the non-normalized WSS in case A (the smallest aneurysm). This suggests that it may not be possible to eliminate the dependence of the results on the viscosity model even via normalization. Xiang et al. recommended that a non-Newtonian model should be used if the maximal diameter of the cerebral aneurysm is 2-fold or greater than the maximal diameter of the parent artery, even if the IA has no bleb [18]. This is because, if the IA has a bleb, the flow in the bleb has a propensity for stagnation; therefore, the influence of non-Newtonian effects cannot be ignored. Case A did not have a bleb, and the maximal diameter of the IA was clearly not 2-fold or greater than that of the parent artery. However, a difference of $25 \%$ in NWSS was observed when comparing the Casson- $\mathrm{H}$ model with the Newtonian model, and thus this cannot be ignored.

The velocity fields obtained with the non-Newtonian models were not similar to those obtained with the Newtonian model in cases B and C. For larger aneurysms, general Newtonian viscosity models may not be appropriate to model the flow field in detail. Moreover, when CFD simulations are applied to quantitative analysis, such as computing NWSS, the results using the general Newtonian viscosity models may be unreliable. From the results of WSS on the parent artery, a difference larger than WSS on the IA sac was observed in the comparison of the two Casson models with the Newtonian model. On the parent artery, the viscosity was not higher than that on the IA sac. That is, the non-Newtonian effect on the parent artery was less than that on the IA sac. Accordingly, not only the non-Newtonian effect but also patient-specific basic viscosity (i.e., converged viscosity in a high strain rate region) should be considered.

The ratio of the parameters obtained with the non-Newtonian model to those obtained with the Newtonian model was compared between the two non-Newtonian models (i.e., the ratio shown in Table 1 with the Casson-H model was subtracted from that with the Casson-L model) in Table 2. Large differences, over $15 \%$, were observed in several parameters such as NWSS and MWSS. This suggests that not only a non-Newtonian model should be introduced but also patient-specific values of blood viscosity should be considered.

In this study, we focused on whether the common viscosity assumption is appropriate for blood flow simulations. While we do not deny the importance of previous studies, our results clearly indicate that differences between hemodynamic parameters with the actual viscosity and those with assumed viscosity depend on the patient-specific viscosity. Therefore, a statistical analysis of parameters computed for groups of cases with the common viscosity assumption may show erroneous trends. Additional studies with a large number of cases and actual viscosity values are necessary. 


\section{Study limitations}

The physical properties of the blood used in this study were obtained from the blood of healthy subjects who were unrelated to the three patients whose data were included in the analysis. However, for IAs of similar size at similar sites, disparities between the actual viscosity value and the assumed value can easily occur in simulations of IA blood flow. Therefore, this study suggests that simulations with the common viscosity assumption can lead to inaccurate results.

To reveal the fundamental mechanism of the influence of non-Newtonian viscosity on hemodynamics, it might be better to use idealized models instead of patient-specific models. However, idealized models were not applied in this study because we did not aim to clarify the mechanism but rather to show how much hemodynamic indices can be affected by the assumption of the Newtonian model when patientspecific geometric models are used in numerical blood flow simulations. We would like to study idealized models in our future work.

\section{Conclusions}

The NWSS values differ by $25 \%$ (0.669 versus 0.502 with the Newtonian and non-Newtonian (Casson-H) model, respectively) and can be processed using the Newtonian model, as shown in the smallest case. Furthermore, the difference between the ratios of NWSS obtained with the non-Newtonian models to those obtained with the Newtonian model was $17.4 \%$. Therefore, CFD simulations using either the common Newtonian or non-Newtonian viscosity assumption could lead to different values from those with a patient-specific viscosity model for hemodynamic parameters, regardless of IA size.

\section{Conflict of interest}

Y.M. and T.I. have received honoraria from Stryker Japan. Y.M. has received honoraria from ASAHI INTECC CO., LTD. Y.M. and H.T. were partially supported by SIEMENS K.K. Japan with a grant provided to our academic institution (Grant No. 35993-00211563). H.T. was supported by NTT DOCOMO, INC. with a donation provided to our academic institution outside the submitted work.

\section{References}

[1] UCAS Japan Investigators. The Natural Course of Unruptured Cerebral Aneurysms in a Japanese Cohort. N Engl J Med. 2012; 366(26): 2474-82.

[2] Shojima M, Oshima M, Takagi K, Torii R, Hayakawa M, Katada K, et al. Magnitude and Role of Wall Shear Stress on Cerebral Aneurysm: Computational Fluid Dynamic Study of 20 Middle Cerebral Artery Aneurysms. Stroke. 2004; 35(11): 2500-5.

[3] Castro MA, Putman CM, Sheridan MJ, Cebral JR. Hemodynamic patterns of anterior communicating artery aneurysms: A possible association with rupture. AJNR Am J Neuroradiol. 2009; 30(2): 297-302.

[4] Castro M, Putman C, Radaelli A, Frangi A, Cebral J. Hemodynamics and Rupture of Terminal Cerebral Aneurysms. Acad Radiol. 2009; 16(10): 1201-7.

[5] Cebral JR, Mut F, Weir J, Putman C. Quantitative characterization of the hemodynamic environment in ruptured and unruptured brain aneurysms. AJNR Am J Neuroradiol. 2011; 32(1): 145-51.

[6] Xiang J, Natarajan SK, Tremmel M, Ma D, Mocco J, Hopkins LN, et al. Hemodynamic-morphologic discriminants for intracranial aneurysm rupture. Stroke. 2011; 42(1): 144-52.

[7] Qian Y, Takao H, Umezu M, Murayama Y. Risk analysis of unruptured aneurysms using computational fluid dynamics technology: preliminary results. AJNR Am J Neuroradiol. 2011; 32(10): 1948-55. 
[8] Lu G, Huang L, Zhang XL, Wang SZ, Hong Y, Hu Z, et al. Influence of hemodynamic factors on rupture of intracranial aneurysms: patient-specific 3D mirror aneurysms model computational fluid dynamics simulation. AJNR Am J Neuroradiol. 2011; 32(7): 1255-61.

[9] Takao H, Murayama Y, Otsuka S, Qian Y, Mohamed A, Masuda S, et al. Hemodynamic differences between unruptured and ruptured intracranial aneurysms during observation. Stroke. 2012; 43(5): 1436-9.

[10] Miura Y, Ishida F, Umeda Y, Tanemura H, Suzuki H, Matsushima S, et al. Low wall shear stress is independently associated with the rupture status of middle cerebral artery aneurysms. Stroke. 2013; 44(2): 519-21.

[11] Meng H, Tutino VM, Xiang J, Siddiqui A. High WSS or Low WSS? Complex interactions of hemodynamics with intracranial aneurysm initiation, growth, and rupture: Toward a unifying hypothesis. AJNR Am J Neuroradiol. 2014; 35(7): 1254-62.

[12] Morales HG, Larrabide I, Geers AJ, Aguilar ML, Frangi AF. Newtonian and non-Newtonian blood flow in coiled cerebral aneurysms. J Biomech. 2013; 46(13): 2158-64.

[13] Yamamoto H, Kawamura K, Omura K, Tokudome S. Development of a compact-sized falling needle rheometer for measurement of flow properties of fresh human blood. Int J Thermophys. 2010; 31(11): 2361-79.

[14] Gijsen FJ, van de Vosse FN, Janssen JD. The influence of the non-Newtonian properties of blood on the flow in large arteries: steady flow in a carotid bifurcation model. J Biomech. 1999; 32(6): 601-8.

[15] Cebral JR, Castro MA, Appanaboyina S, Putman CM, Millan D, Frangi AF. Efficient pipeline for image-based patientspecific analysis of cerebral aneurysm hemodynamics: technique and sensitivity. IEEE Trans Med Imaging. 2005; 24(4): 457-67.

[16] Valencia AA, Guzmán AM, Finol EA, Amon CH. Blood flow dynamics in saccular aneurysm models of the basilar artery. J Biomech Eng. 2006; 128(4): 516-26.

[17] Fisher C, Rossmann JS. Effect of non-newtonian behavior on hemodynamics of cerebral aneurysms. J Biomech Eng. 2009; 131(9): 091004.

[18] Xiang J, Tremmel M, Kolega J, Levy EI, Natarajan SK, Meng H. Newtonian viscosity model could overestimate wall shear stress in intracranial aneurysm domes and underestimate rupture risk. J Neurointerv Surg. 2012; 4(5): 351-7.

[19] Evju Ø, Valen-Sendstad K, Mardal K-A. A study of wall shear stress in 12 aneurysms with respect to different viscosity models and flow conditions. J Biomech. 2013; 46(16): 2802-8.

[20] Hippelheuser JE, Lauric A, Cohen AD, Malek AM. Realistic non-Newtonian viscosity modeling highlights hemodynamic differences between intracranial aneurysms with and without surface blebs. J Biomech. 2014; 47(15): 3695-703.

[21] Ford MD, Alperin N, Lee SH, Holdsworth DW, Steinman DA. Characterization of volumetric flow rate waveforms in the normal internal carotid and vertebral arteries. Physiol Meas. 2005; 26(4): 477-88.

[22] Venkatesan J, Sankar DS, Hemalatha K, Yatim Y. Mathematical analysis of Casson fluid model for blood rheology in stenosed narrow arteries. J Appl Math. 2013: 2013. Available from: http://dx.doi.org/10.1155/2013/583809.

[23] Cebral JR, Castro MA, Appanaboyina S, Putman CM, Millan D, Frangi AF. Efficient pipeline for image-based patientspecific analysis of cerebral aneurysm hemodynamics: Technique and sensitivity. IEEE Trans Med Imaging. 2005; 24(4): 457-67.

[24] Suzuki T, Yamamoto H, Kawamura K, et al. Automatic flow analysis for human blood at low shear rate range. In: Proceedings of the 6th International Multi-Conference on Engineering and Technological Innovation, Orlando, Florida. 9-12 July 2013. Available from: http://www.iiis.org/CDs2013/CD2013SCI/IMETI_2013/PapersPdf/FA841NM.pdf

[25] Zhang Y, Takao H, Murayama Y, Qian Y. Propose a wall shear stress divergence to estimate the risks of intracranial aneurysm rupture. ScientificWorldJournal. Jan 2013; 2013: 508131. Available from: http://www.ncbi.nlm.nih.gov/ pmc/articles/PMC3804446/.

[26] Jing L, Fan J, Wang Y, Li H, Wang S, Yang X, et al. Morphologic and Hemodynamic Analysis in the Patients with Multiple Intracranial Aneurysms: Ruptured versus Unruptured. PLoS One. 2015; 10(7): e0132494. Available from: http://dx. plos. org/10.1371/journal. pone.0132494.

[27] Xiang J, Tutino VM, Snyder KV, Meng H. CFD: Computational Fluid Dynamics or Confounding Factor Dissemination? The Role of Hemodynamics in Intracranial Aneurysm Rupture Risk Assessment. AJNR Am J Neuroradiol. 2014; 35(10): 1849-57. 